American Journal of Applied Sciences 7 (3): 352-359, 2010

ISSN 1546-9239

(C) 2010Science Publications

\title{
Whole Body Vibration Exposure to Train Passenger
}

\author{
${ }^{1}$ A.R. Ismail, ${ }^{2}$ M.Z. Nuawi, ${ }^{2}$ C.W. How, ${ }^{2}$ N.F. Kamaruddin, ${ }^{2}$ M.J.M. Nor and ${ }^{2}$ N.K. Makhtar \\ ${ }^{1}$ Faculty of Mechanical Engineering, University Malaysia Pahang, \\ 26600 Pekan, Pahang, Malaysia \\ ${ }^{2}$ Department of Mechanical and Materials Engineering, \\ Faculty of Engineering and Built Environment, \\ University Kebangsaan Malaysia, 43600 UKM Bangi, Malaysia
}

\begin{abstract}
Problem statement: Train is one of the important and famous public transportations in the whole world. High magnitude of whole-body vibration formed by the train may cause diseases and health problems to the human especially a low back pain. This study will give an account of daily exposure to vibration $\mathrm{A}(8)$ and Vibration Dose Value (VDV) exposed to the passengers travelling in the train and the effects produced by the exposure towards human body. Approach: One national train travelled from East Coast to the South has been chosen to conduct the study. The whole-body vibration exposure was measured in $8 \mathrm{~h}$, which is equal to the duration for normal occupation condition. All the data was computed by using IEPE (ICP ${ }^{\mathrm{TM}}$ ) accelerometer sensor connected to DT9837 device which is capable to measure and analyze vibration effectively. The vibration results attained were displayed in personal computer by using custom Graphical User Interface (GUI). MATLAB software was used to interpret the data obtained. From the results shown, the whole-body vibration exposure level can be determined. Results: The values of daily exposure to vibration A(8) and Vibration Dose Value (VDV) in Experiment 3 were $0.3749 \mathrm{~m} \mathrm{sec}^{-2}$ and $1.2513 \mathrm{~m} \mathrm{sec}^{-1.75}$ respectively. Conclusion: It can be concluded that the whole-body vibration absorbed by human body enhanced when the duration of vibration exposure and the total of the trips that has been passed by the passengers increased. This can be proved by the increasing of the value of daily exposure to vibration A(8) and Vibration Dose Value (VDV) calculated in the study.
\end{abstract}

Key words: Whole-body vibration, vibration dose value, low back pain

\section{INTRODUCTION}

Ergonomics is the application of scientific principles, methods and data drawn from a variety of disciplines to the development of engineering systems in which people play a significant role. Among the basic disciplines are psychology, cognitive sciences, physiology, biomechanics, applied physical anthropometry and industrial systems engineering (Kroemer et al., 2003). Matilla (1996) mentioned that the importance of safety and ergonomics had grown significantly. The latest technology had increased the option to broaden the ergonomics and safety features of products and equipment. However, it will also create new risks and the way to manage it would become more complicated. Therefore, it is important for the designer to use ergonomic knowledge in making decision during of machines, equipment, products and systems. There is substantial epidemiologic evidence of associations between physical ergonomics exposures at the workplace, such as lifting, constrained postures, repetitive movements, fast work pace, heavy material manual handling, forceful exertions and vibration and the occurrence of upper extremity musculoskeletal disorders (Bernard, 1997; Grieco et al., 1998; Hagberg et al., 1995; National Research Council, 2001; Van Der Windt et al., 2000). To be more specific, ergonomics (also called human factors or human engineering in the United States) defined as the study of human characteristics for the appropriate design of the living and work environment. Its fundamental aim is that all humanmade tools, devices, equipment, machines and environments should advance, directly or indirectly, the safety, well-being and performance of human beings (Kroemer et al., 2003). Several ergonomic interventions, such as employee training, redesign of process tools or workstations and improvement of work conditions, were suggested to tackle musculoskeletal

Corresponding Author: A.R. Ismail, Faculty of Mechanical Engineering, University Malaysia Pahang, 26600 UMP Pekan, Pahang, Malaysia 
problems in industries (Wang et al., 2003; Weestgard and Winkel, 1997).

Various definitions have been given to WholeBody Vibration (WBV) by dictionaries, companies and authors themselves. From the Directive 2002/44/EC of the European Parliament and of the Council, the term 'whole-body vibration' means the mechanical vibration that, when transmitted to the whole body, entails risks to the health and safety of workers, in particular lowerback morbidity and trauma of the spine (OJEC, 2000). WBV is defined as vibration occurring when a greater part of the body weight is supported on a vibrating surface. WBV principally occurs in vehicles and wheeled working machines. In most cases exposure to WBV occurs in a sitting position and the vibration is then primarily transmitted through the seat pan, but also through the back rest. WBV may impair performance and comfort. It has also been claimed to contribute to the development of various injuries and disorders. In many work situations WBV is therefore an evident and annoying occupational health problem (Griffin, 1990).

Low Back Pain (LBP) is among the most common and costly health problems (Garg and Moore, 1992; Tulder et al., 1995). Occupational, non-occupational and individual risk factors play a role in the development, the duration and the recurrence of LBP. Several critical reviews have discussed the evidence on occupational risk factors for back disorders (Wilder and Pope, 1996; Burdorf and Sorock, 1997; Bovenzi and Hulshof, 1999; Lings and Leboeuf-Yde, 2000; Waddell and Burton, 2000). All these reviews conclude that there is strong epidemiological evidence for a relation between occupational exposure to WBV and LBP. In five European countries (Belgium, Germany, Netherlands, France, Denmark), LBP and spinal disorders due to WBV are currently recognized as an occupational disease (Hulshof et al., 2002). However, high exposures and adverse effects still occur as WBV is a common occupational risk factor for LBP, affecting $4-8 \%$ of the workforce in industrialized countries (Palmer et al., 2000). Important high risk groups are drivers of off-road vehicles (for example, earth moving, forestry and agricultural machines), drivers of forklift trucks, lorries, or buses, crane operators and helicopter pilots.

\section{MATERIALS AND METHODS}

Whole-body vibration measurement was done according to ISO 263-1:1997. The triaxial accelerometer sensor was located between the passenger contact points with the vibration source.

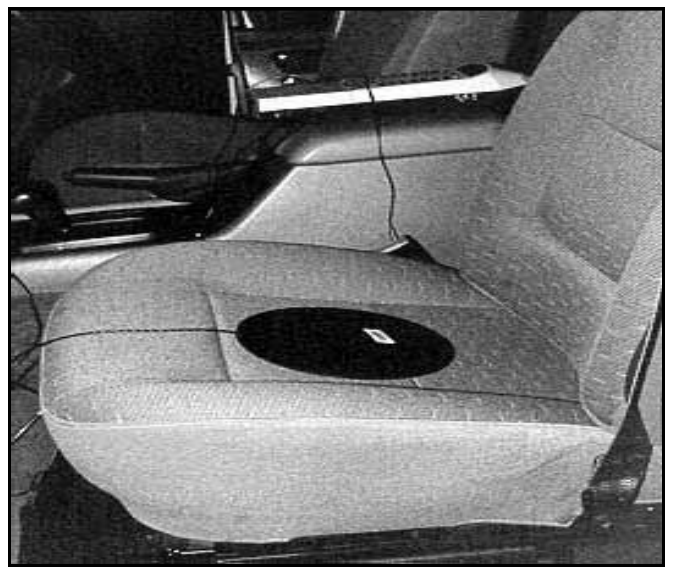

Fig. 1: Triaxial accelerometer sensor used for WBV measurement

Table 1: Location measurement

\begin{tabular}{ll}
\hline Experiment & Location \\
\hline 1 & From kajang to seremban \\
2 & From seremban to gemas \\
3 & From segamat to tampin \\
\hline
\end{tabular}

One passenger was picked randomly in the train. Then the passenger sat on the accelerometer, for example as in Fig. 1.

In this study, the assessment of whole-body vibration was completed by deciding number of sampling rate to 1000 samples $\mathrm{sec}^{-1}$. Compution of the exposure time was set to $8 \mathrm{~h}$ for each experiment, which equal to the duration for normal occupation stipulation. The study has been conducted at different locations. The location measurement for each experiment was explained in Table 1. After the accelerometer and DT9837 instrument were connected, the process of collecting the data acquisition of the train vibration was started. The total vibration of each axes which were $\mathrm{x}, \mathrm{y}$ and $\mathrm{z}$-axis felt by the passenger was displayed in a plotted graph by using Mat lab software.

Whole-body vibration measurement explored by the passenger was done three times at different train trip areas. Among the areas passing by the train were namely from Kajang to Seremban, from Seremban to Gemas and from Segamat to Tampin.

Description of subject: Excessive exposure of wholebody vibration usually occurred at working area which involved long duration of exposure and high-level of vibration magnitude. Train is one of the most public transportations that produced high magnitude of vibration. The one national train travelled from East Coast to the South has been chosen to conduct the study. 
Am. J. Applied Sci., 7 (3): 352-359, 2010

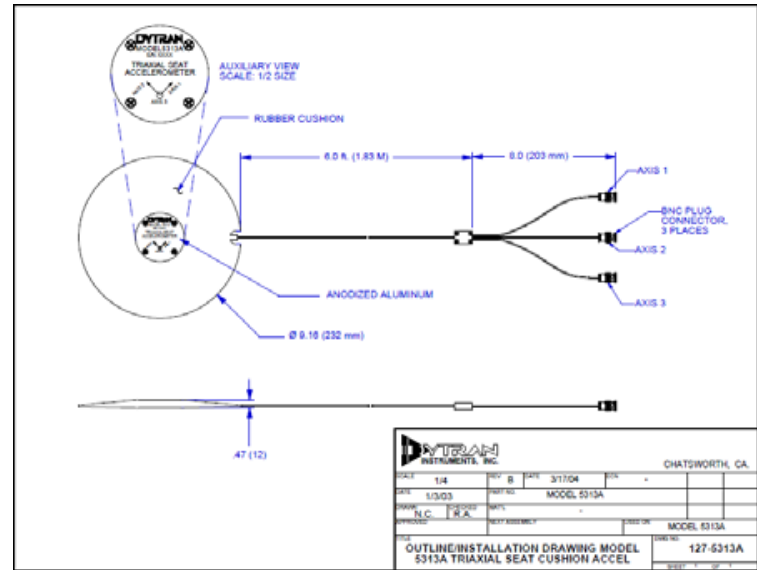

Fig. 2: Triaxial seat accelerometer (DYTRAN model 5313A)

Equipments: There were two devices used in the study which were IEPE $\left(\mathrm{ICP}^{\mathrm{TM}}\right)$ accelerometer sensor and DT9837 instrument.

Based on Fig. 2, the IEPE (ICP ${ }^{\mathrm{TM}}$ ) accelerometer sensor (also known as triaxial seat accelerometer) been used in this study was DYTRAN Model 5313A. The sensor was utilized to assess the vibration level. The accelerometer consists of a piezoelectric element connected to a known mass. When the accelerometer is vibrated, the mass applies force to the piezoelectric element, generating an electrical charge that is proportional to the applied force. Then this charge was deliberated to determine the vibration characteristics. Figure 3 showed how the accelerometer works. Most accelerometers require a current source of $4 \mathrm{~mA}$ and a compliance voltage of at least $18 \mathrm{~V}$ to drive their internal circuitry. Other accelerometers require a $2 \mathrm{~mA}$ current source, but have limitations in cable length and bandwidth.

The DT9837 instrument was a highly accurate five channel data acquisition module that is ideal for portable noise and vibration measurements. It has 4 simultaneous, 24 bit A/D channels for high resolution measurements. This instrument supports for four IEPE inputs, including $4 \mathrm{~mA}$ current sources. Portable operation can be done by the DT9837 because no external power supply needed and runs on USB power. The DT9837 has tachometer input support in the A/D data stream for synchronizing measurements. Sampling rate of over $52 \mathrm{kHz}$ was produced by this instrument. It has low frequency measurements supported with a wide pass band of 0.5-25.8 kHz (0.49 × sampling frequency). The DT9837 was a programmable trigger for analog input operations for maximum flexibility. Figure 4 and Table 2 showed the DT9837 model and the summary features of the instrument.

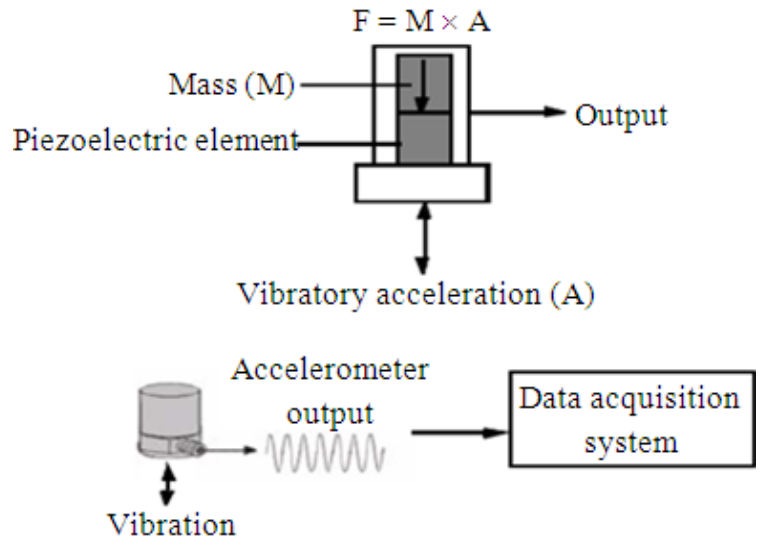

Fig. 3: How accelerometers work

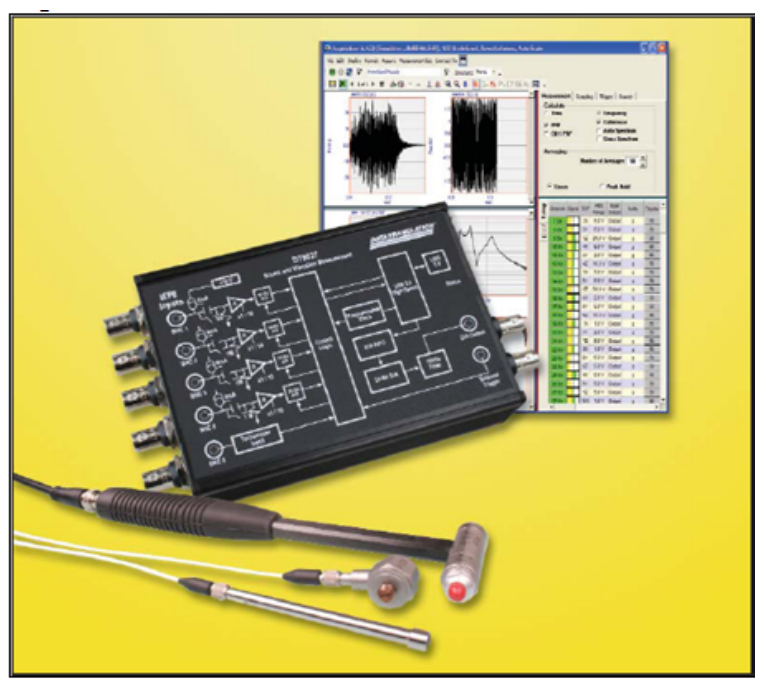

Fig. 4: DT9837 model

Table 2: Summary features of DT9837

\begin{tabular}{|c|c|c|c|c|}
\hline \multicolumn{5}{|c|}{ Summery of features } \\
\hline $\begin{array}{l}\mathrm{A} / \mathrm{D} \\
\text { throughput } \\
\text { per channel } \\
\end{array}$ & $\begin{array}{l}\mathrm{D} / \mathrm{A} \\
\text { channels }\end{array}$ & $\begin{array}{l}\text { Tachometer } \\
\text { input }\end{array}$ & $\begin{array}{l}\text { Simultaneous } \\
\text { subsystem } \\
\text { operation }\end{array}$ & Application \\
\hline $\begin{array}{l}52.734 \mathrm{kHz} 4 \\
\text { IEPE inputs } \\
\text { simultaneous }\end{array}$ & $\begin{array}{l}1 \text { waveform } \\
\text { or single } \\
\text { value }\end{array}$ & $\begin{array}{l}1 \text { synchronous } \\
\text { to analog data } \\
\text { steam }\end{array}$ & Yes & $\begin{array}{l}\text { Vibration, } \\
\text { acoustics, } \\
\text { sonar }\end{array}$ \\
\hline
\end{tabular}

Description of software and custom Graphical User Interface (GUI): In this study, MATLAB software was applied to analyze the vibration signal gathered by DT9837 instrument from USB port. The MATLAB Graphical User Interface (GUI) scripts have been examined by using GUIDE function for ease measurement and assessment of WBV exposure. 
Am. J. Applied Sci., 7 (3): 352-359, 2010

Table 3: Whole-body vibration measurent data collected in train

\begin{tabular}{|c|c|c|c|c|c|c|}
\hline \multirow[b]{2}{*}{ Analysis method } & \multicolumn{2}{|c|}{ Experiment 1} & \multicolumn{2}{|c|}{ Experiment 2} & \multicolumn{2}{|c|}{ Experiment 3} \\
\hline & $\begin{array}{l}\text { From } \\
\text { Kajang }\end{array}$ & $\begin{array}{l}\text { To } \\
\text { Seremban }\end{array}$ & $\begin{array}{l}\text { from } \\
\text { Seremban }\end{array}$ & $\begin{array}{l}\text { To } \\
\text { Gemas }\end{array}$ & $\begin{array}{l}\text { From } \\
\text { Seremban }\end{array}$ & $\begin{array}{l}\text { To } \\
\text { Tampin }\end{array}$ \\
\hline Daily exposure to vibration $\mathrm{A}(8)$ & \multicolumn{2}{|c|}{$0.3221 \mathrm{~m} \mathrm{sec}^{-2}$} & \multicolumn{2}{|c|}{$0.2884 \mathrm{~m} \mathrm{sec}^{-2}$} & \multicolumn{2}{|c|}{$0.3749 \mathrm{msec}^{-2}$} \\
\hline Exposure points system & \multicolumn{2}{|c|}{41.4867 point } & \multicolumn{2}{|c|}{33.2716 point } & \multirow{2}{*}{\multicolumn{2}{|c|}{$\begin{array}{l}56.206 \text { point }^{-1.75} \\
1.2513 \mathrm{~m} \mathrm{sec}^{-1.7}\end{array}$}} \\
\hline Vibration Dose Value (VDV) & \multicolumn{2}{|c|}{$1.1014 \mathrm{~m} \mathrm{sec}^{-1.75}$} & \multicolumn{2}{|c|}{$1.0973 \mathrm{~m} \mathrm{sec}^{-1.75}$} & & \\
\hline Daily exposure action value time $\left(0.5 \mathrm{~m} \mathrm{sec}^{-2}\right)$ & \multicolumn{2}{|c|}{$9 \mathrm{~h} 50 \mathrm{~min}$} & \multicolumn{2}{|c|}{12 h 16 min } & \multicolumn{2}{|c|}{$7 \mathrm{~h} 16 \mathrm{~min}$} \\
\hline Daily exposure limit value time $\left(1.15 \mathrm{~m} \mathrm{sec}^{-2}\right)$ & \multicolumn{2}{|c|}{$52 \mathrm{~h} 3 \mathrm{~min}$} & \multicolumn{2}{|c|}{$64 \mathrm{~h} 54 \min$} & \multicolumn{2}{|c|}{38 h 25 min } \\
\hline Points per $h$ & 5.1858 & & 4.159 poin & & \multicolumn{2}{|c|}{7.0258 point } \\
\hline $\begin{array}{l}\text { Time achieving } \\
1.75 \mathrm{~m} \mathrm{sec}^{-1.75}\end{array}$ & \multicolumn{2}{|c|}{$1 \mathrm{~h} 29 \mathrm{~min}$} & \multicolumn{2}{|l|}{$1 \mathrm{~h} 30 \mathrm{~min}$} & \multicolumn{2}{|l|}{$53 \mathrm{~min}$} \\
\hline
\end{tabular}

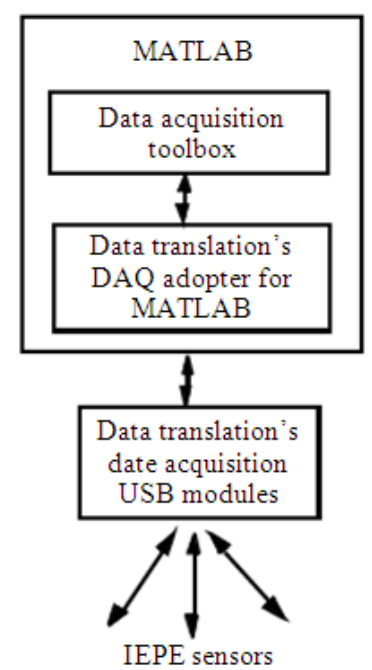

Fig. 5: Flow chart of data acquisition process

From this MATLAB script, three graphs of each axes been meditated for current analysis. Besides, the data and vibration signal can be saved in the personal computer for next analysis. Thus, the total of daily exposure to vibration towards human can be evaluated through the accelerometer sensor, DT9837 instrument and this MATLAB software. MATLAB was a well known interactive software environment for data acquisition and analysis, report generation and test system development. It provides a complete set of tools for acquiring and analyzing analog and digital input output signals from a variety of PC-compatible data acquisition hardware. The MATLAB Data Acquisition Toolbox configured the external hardware devices, read data into MATLAB and Simulink for immediate analysis and send out data for controlling the system. The diagram shown in Fig. 5 depicts an example using MATLAB and the MATLAB data acquisition toolbox with data translation's DT9837 to acquire vibration data from USB modules. Notice that the data translation provides an interface layer, called the DAQ adaptor for MATLAB, which allows the MATLAB data acquisition toolbox to communicate with data translation's hardware, while the data acquisition toolbox is collecting data, MATLAB can analyze and visualize the data.

\section{RESULTS}

From the three experiments done, daily exposure to vibration A (8) value and Vibration Dose Value (VDV) and exposure points value were evaluated by using formula (1), (2) and (3). But, by employed the MATLAB Graphical User Interface (GUI), the calculation of those values was done by choosing the analysis method from the organize MATLAB menu. When the option was made followed the passenger's need, the calculated values completed by connect the update button. Hence, the results were displayed in the custom made Graphical User Interface (GUI).

Daily exposure to vibration $\mathrm{A}(8)$ :

$A(8)=$ vibration value $\left(\frac{m}{S^{2}}\right) \times \sqrt{\frac{\text { exp osure time }(\min )}{480(\min )}}$

Vibration Dose Value (VDV):

$\operatorname{VDV}=\left(\int_{0}^{\mathrm{T}} \mathrm{a}^{4}(\mathrm{t}) \mathrm{dt}\right)^{0.25}$

Where:

$\mathrm{a}(\mathrm{t})=$ Frequency-weighted acceleration $\left(\mathrm{m} \mathrm{sec}^{-2}\right)$

$\mathrm{T}=$ The total period of the day during which vibration may occur (s)

Exposure points value:

exp osure points $=2 \times(\text { vibration value })^{2}$

All the data obtained in the experiment were organized in Table 3 . Whole-body vibration graphs were demonstrated in Fig. 6. For Fig. 6a, the graph of whole-body vibration was collected namely from Kajang to Seremban, while Fig. 6b was from Seremban to Gemas and Fig. 6c from Segamat to Tampin. 
Am. J. Applied Sci., 7 (3): 352-359, 2010

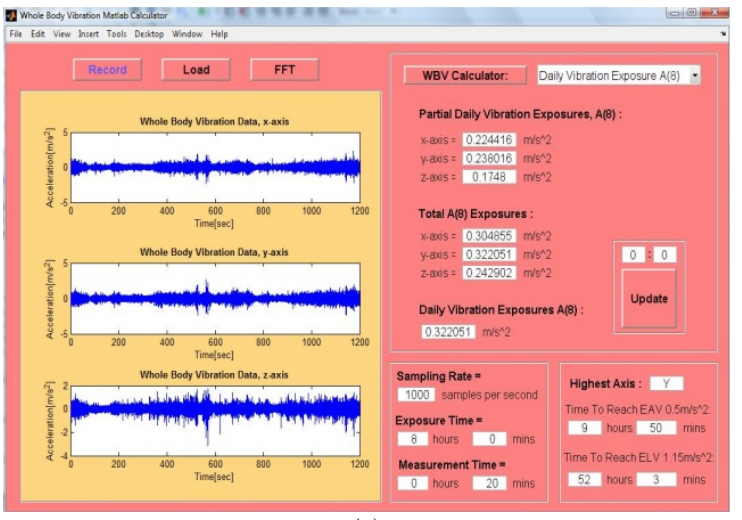

(a)

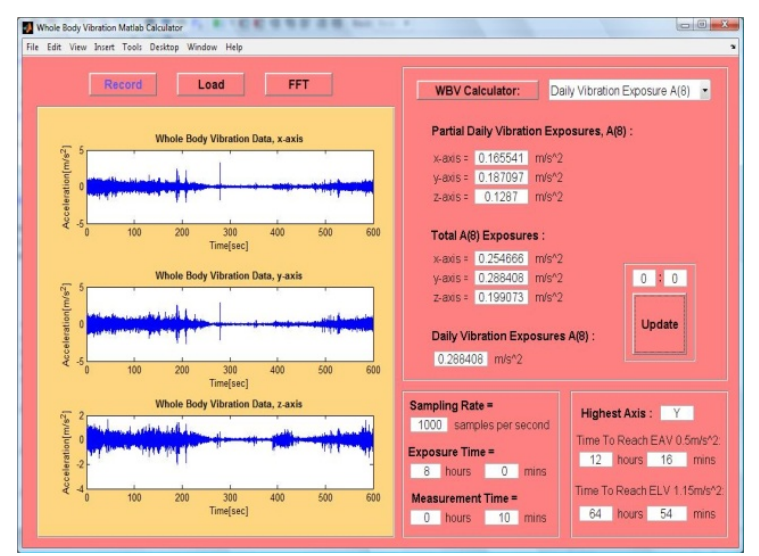

(b)

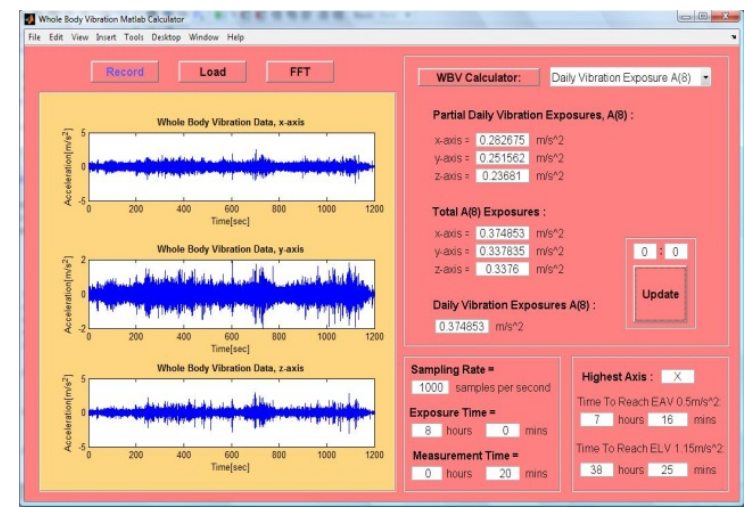

(c)

Fig. 6: Whole-body vibration custom data acquisition system (a) from Kajang to Seremban, (b) from Seremban to Gemas and (c) from Segamat to Tampin

Figure 7 showed the calculation of exposure points system. The Vibration Dose Value (VDV) measurement was illustrated in Fig. 8.

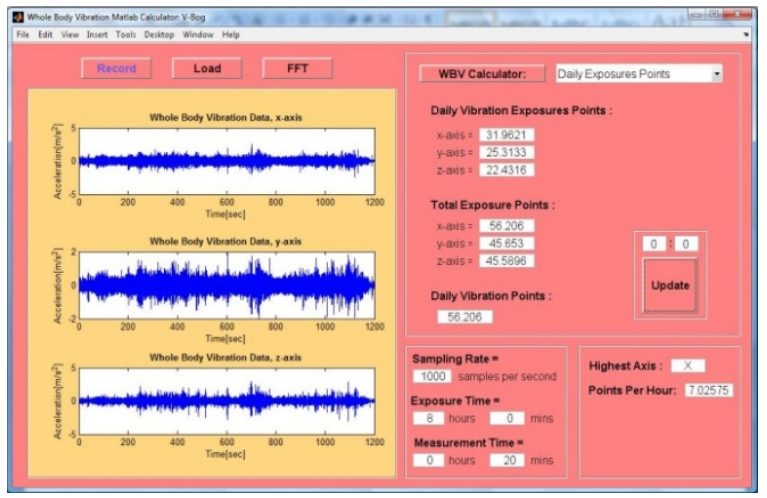

Fig. 7: Exposure points system calculation

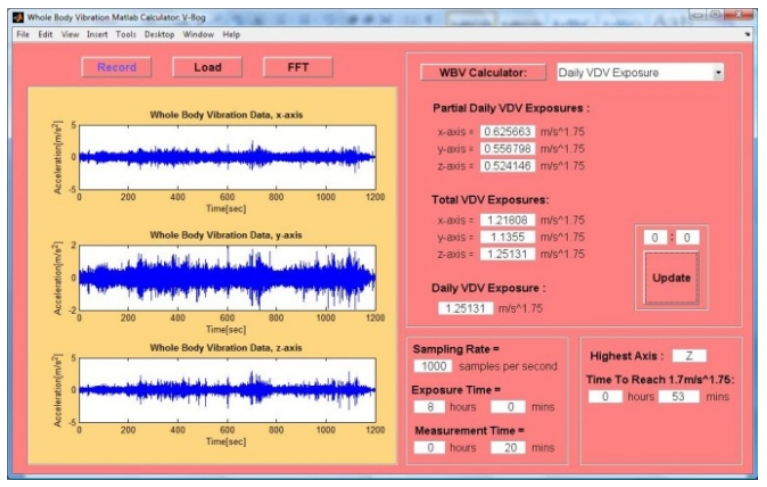

Fig. 8: Vibration Dose Value (VDV) computation

\section{DISCUSSION}

From the results attained, the frequency weighted acceleration value indicated in the study was closely to the permissible value of exposure limit stated according to ISO 2631-1:1997. Therefore, the high magnitude of WBV may cause musculoskeletal disorders to the train passengers.

The basic method (frequency weighted r.m.s. method) in ISO 2631-1 is primarily applicable to assessment of health risks from stationary vibrations not containing severe multiple or single event shocks. Single event shocks can be analyzed with the additional method running r.m.s. in 2631-1, although there is no information on health risk levels. The additional method VDV (frequency weighted fourth power vibration dose value) is more sensitive to shocks than the basic method, but it will still underestimate the health risk of vibration containing severe shocks in comparison to the health risk of vibration not containing severe shocks. The EU Physical Agents Directive uses the basic method for assessment of health risk with VDV as an alternative. The two methods give different assessment results. 
Am. J. Applied Sci., 7 (3): 352-359, 2010

Table 4: Standard value of RMS acceleration

\begin{tabular}{ll}
\hline Exposure limit & RMS acceleration \\
\hline $8 \mathrm{~h}$ & $2.8 \mathrm{~m} \mathrm{sec}^{-2}$ \\
$4 \mathrm{~h}$ & $4.0 \mathrm{~m} \mathrm{sec}^{-2}$ \\
$2.5 \mathrm{~h}$ & $5.6 \mathrm{~m} \mathrm{sec}^{-2}$ \\
$1 \mathrm{~h}$ & $11.2 \mathrm{~m} \mathrm{sec}^{-2}$ \\
$30 \mathrm{~min}$ & $16.8 \mathrm{~m} \mathrm{sec}^{-2}$ \\
$5 \mathrm{~min}$ & $27.4 \mathrm{~m} \mathrm{sec}^{-2}$ \\
$1 \mathrm{~min}$ & $61.3 \mathrm{~m} \mathrm{sec}^{-2}$ \\
\hline
\end{tabular}

The root-mean-square (r.m.s) vibration magnitude is expressed in terms of the frequency weighted acceleration at the seat of a seated person or the feet of a standing person, it is expressed in units of meters per second squared (m $\mathrm{sec}^{-2}$ ). The r.m.s vibration magnitude represents the average acceleration over a measurement period. It is the highest of three orthogonal axes values $\left(1.4 \mathrm{a}_{\mathrm{wx}}, 1.4 \mathrm{a}_{\mathrm{wy}}\right.$ or $\left.\mathrm{a}_{\mathrm{wz}}\right)$ that are used for the exposure assessment.

For knowledge, the frequency weighted acceleration value which less than $0.45 \mathrm{~m} \mathrm{sec}^{-2}$ showed that there was no negative health effect expected. Whilst the frequency weighted value in between 0.45 and $0.90 \mathrm{~m} \mathrm{sec}^{-2}$ explained that the negative health effects still can be accepted. But, the frequency weighted acceleration value greater than $0.90 \mathrm{~m} \mathrm{sec}^{-2}$, high risks of bad health problems were anticipated.

The data from Table 4 indicated the r.m.s acceleration value for exposure limit in $8 \mathrm{~h}$. The passengers exposed to the whole-body vibration exposure must not exceed this standard value. Otherwise, the passengers may have an experience of bad health problems.

The results of this study indicated that in Experiment 3, the values of daily exposure to vibration A (8) and Vibration Dose Value (VDV) were much higher than the other two experiments. The values of daily exposure to vibration A (8) and Vibration Dose Value (VDV) were $0.3749 \mathrm{~m} \mathrm{sec}^{-2}$ and $1.2513 \mathrm{~m} \mathrm{sec}^{-1.75}$ respectively. It seems possible that these results were due to indelicate track passed by the train, the train operation style and speed differences compared to Experiment 1 and 2. In addition, the daily exposure action value time only required $7 \mathrm{~h} 16 \mathrm{~min}$ to meet the standardized value of $0.5 \mathrm{~m} \mathrm{sec}^{-2}$ to an $8 \mathrm{~h}$ reference period. Surprisingly, this result was found to exceed the standard time of whole-body vibration assessment which was $8 \mathrm{~h}$ stated in ISO 2631-1:1997. The reason for this is not clear but it may have something to do with the speed of the train that generated high magnitude of vibration value to the train. The high magnitude of whole-body vibration exposure produced by the train may contribute to musculoskeletal disorders to the passengers. In reviewing the literature, there was found the relation between occupational vehicles and whole-body vibration exposure that lead to musculoskeletal disorders.

The term musculoskeletal disorder refers to conditions that involve the nerves, tendons, muscles and supporting structures of the body (Bernard, 1997). Exposure to WBV is another occupational risk factor that may cause LBP in participants of occupational vehicles (Bovenzi and Hulshof, 1999). In western countries an estimated $4-7 \%$ of all employees are exposed to potentially harmful WBV. Experimental studies have found that resonance frequencies of most of the organs or other parts of the body lie between 1 and $10 \mathrm{~Hz}$, which are in the range of frequencies found in occupational machines and vehicles. 6 million workers are exposed to WBV typically while in a seated position including delivery vehicles drivers, forklift operators, helicopters pilots and construction equipment operators (Griffin, 2006). Tractor drivers have reported $61-94 \%$ prevalence of LBP and pathological changes in the spine and heavy-equipment drivers report $70 \%$ prevalence of LBP. WBV is recognized as an important risk factor for occupational LBP in a variety of occupational groups (Joubert and Leslie, 2007). At least four European countries have placed WBV injury on their scheduled lists of occupational diseases (Hulshof et al., 2002). Among such physical exposures encountered in working conditions, WBV has repeatedly been identified as a risk factor for LBP (Santos et al., 2008). Several epidemiologic studies conducted in the past several years found strong evidence for a correlation between exposure to WBV and the occurrence of LBP (Noorloos et al., 2008). The National Research Council (2001) reported that there is evidence of a "clear relationship between back disorders and whole-body vibration”. Joubert and Leslie (2007) had determined the association between back belt usage and back pain amongst forklift drivers exposed to WBV. LBP has been identified as one of the most costly disorders among the worldwide working population and sitting has been associated with risk of developing LBP (Liss et al., 2007). It was showed that sustaining trunk sitting postures corresponding to mining vehicle operators generates back muscle fatigue and postural balance (Santos et al., 2008). On the other hand, Noorloos et al. (2008) had been concluded that occupational participants exposed to WBV, with a high BMI do not have an increased risk for the development of LBP, so the focus should be on other factors.

\section{CONCLUSION}

WBV gained by human body increased when the duration of vibration exposure and the total train trips experienced by the subject enlarged. This phenomena 
can be proved by the increasing of daily of exposure to vibration $A(8)$ value and Vibration Dose Value (VDV). Hence, it was clearly explained that most of the train passengers especially at the national train located at Malaysia were exposed to worse WBV during their travelling time because the frequency-weighted acceleration value indicated in the study was closely to the value of exposure limit value according to ISO 2631-1:1997. Consequently, this condition may cause health problems to the passengers. Empirical studies showed that there was a relation between an occupational vehicles and whole-body vibration that lead to musculoskeletal disorders. But, from the scenario of Malaysian population, there is a deficient research on this problem. Because of insufficient knowledge of diseases affected by WBV, the passengers find difficulty to know exactly the exposure of WBV to them and how much they have been exposed. As a conclusion, more studies are needed to provide clear evidence of the association between WBV and musculoskeletal disorders especially on Malaysian occupational vehicles. A further study with more focus on the train drivers is therefore suggested.

\section{REFERENCES}

Bernard, B.P., 1997. Musculoskeletal disorders and workplace factors: A critical review of epidemiologic evidence for work-related musculoskeletal disorders of the neck, upper extremity and low back. National Institute for Occupational Safety and Health. http://www.cdc.gov/niosh/docs/97-141/

Bovenzi, M. and C.T.J. Hulshof, 1999. An updated review of epidemiologic studies on the relationship between exposure to whole-body vibration and low back pain. Int. Arch. Occup. Environ. Health, 72: 351-365. DOI: 10.1007/s004200050387

Burdorf, A. and G. Sorock, 1997. Positive and negative evidence of risk factors for back disorders. Scand. J. Work Environ. Health, 23: 243-256.

Garg, A. and J.S. Moore, 1992. Epidemiology of lowback pain in industry. Occup. Med., 7: 593-60.

Grieco, A., G. Molteni, G. De Vito and N. Sias, 1998. Epidemiology of musculoskeletal disorders due to biomechanical overload. Ergonomics, 41: 12531260. DOI: $10.1080 / 001401398186298$

Griffin, M.J., 1990. Handbook of Human Vibration. 1st Edn., Academic Press, London, ISBN: 0123030412, pp: 1008.

Griffin, M.J., 2006. Health effects of vibration-the known and unknown. Proceeding of the 1st American Conference on Human Vibration, Morgan Town, DHHS/CDC/NIOSH, WV., pp: 3-4.
Hagberg, M., B. Silverstein, R. Wells, M.J. Smith and H.W. Hendrick, 1995. Work Related Musculoskeletal Disorders (WMSDs): A Reference Book for Prevention, Taylor and Francis, London, Bristol, pp: 421.

Hulshof, C.T.J., G. Van Der Laan, I.T.J. Braam and J.H.A.M. Verbeek, 2002. The fate of Mrs. Robinson: Criteria for recognition of whole-body vibration injury as an occupational disease. J. Sound Vibrat., 253: 185-194. DOI: 10.1006/jsvi.2001.4255

Joubert, D.M. and L. Leslie, 2007. A cross-sectional study of back belt use and low back pain amongst forklift drivers. Int. J. Ind. Ergon., 37: 505-513. DOI: 10.1016/j.ergon.2007.02.005

Kroemer, K., H.K. Kroemer and K.K. Elbert, 2003. Ergonomics How to Design for Ease and Efficiency. 2nd Edn., Prentice Hall, ISBN: 0-13752478-1.

Lings, S. and C. Leboeuf-Yde, 2000. Whole-body vibration and low back pain: A systematic, critical review of the epidemiological literature 1992-1999. Int. Arch. Occup. Environ. Health, 73: 290-297. DOI: $10.1007 / \mathrm{s} 004200000118$

Liss, A.M., K.M. Black, H. Korn, and M. Nordin, 2007. Association between sitting and occupational LBP. Eur. Spine J., 16: 283-298. DOI: 10.1007/s00586006-0143-7

Matilla, M., 1996. Computer-aided ergonomics and safety-a challenge for integrated ergonomics. Int. J. Ind. Ergon., 17: 309-314.

National Research Council, 2001. Institute of Medicine, Musculoskeletal Disorders and the Workplace: Low Back and Upper Extremities. National Academy Press, Washington DC., ISBN: 0-30907284-0, pp:512.

Noorloos, D., T. Tersteeg, I.J.H. Tiemessen, C.T.J. Hulshof and M.H.W. Frings-Dresen, 2008. Does body mass index increase the risk of low back pain in a population exposed to whole body vibration. Applied Ergon., 39: 779-785. DOI: 10.1016/j.apergo.2007.11.002

OJEC., 2002. Directive 2002/44/EC of the European Parliament and of the Council of 25 June 2002. Offic. J. Eur. Commut. http://www.btbtools.com/European\%20HAV\%20D irective.pdf

Palmer, K.T., M.J. Griffin and H. Bendall, 2000. Prevalence and pattern of occupational exposure to whole body vibration in Great Britain: Findings from a national survey. Occup. Environ. Med., 57: 229-236. DOI: 10.1136/oem.57.4.229 
Santos, B.R., C. Lariviere, A. Delisle, A. Plamondon, P.E. Boileau and D. Imbeau, 2008. A laboratory study to quantify the biomechanical responses to whole-body vibration: The influence on balance, reflex response, muscular activity and fatigue. Int. J. Ind. Ergon., 38: 626-639. DOI: 10.1016/j.ergon.2008.01.015

Tulder, V., M.W., B.W. Koes and L.M. Bouter, 1995. A cost-of-illness study of back pain in the Netherlands. Pain, 62: 233-240.

Van Der Windt, D.A.W.M., E. Thomas, D.P. Pope, A.F. De Winter and G.J. Macfarlane, 2000. Occupational risk factors for shoulder pain: A systematic review. Occup. Environ. Med., 57: 433-442. DOI: 10.1136/oem.57.7.433

Waddell, G. and A.K. Burton, 2000. Occupational health guidelines for the management of low back pain at work: Evidence review. Occup. Med., 51: 124-135. DOI: 10.1093/occmed/51.2.124
Wang, M.J.J., H.C. Chung and H.C. Wu, 2003. The evaluation of manual FOUP handling in $300 \mathrm{~mm}$ wafer FAB. IEEE Trans. Semicond. Manuf., 16: 551-554. DOI: 10.1109/TSM.2003.815207

Weestgard, R.H. and J. Winkel, 1997. Ergonomic intervention research for improved musculoskeletal health: A critical review. Int. J. Ind. Ergon., 20: 463-500. DOI: 10.1016/S0169-8141(96)00076-5

Wilder, D.G. and M.H. Pope, 1996. Epidemiological and aetiological aspects of low back pain in vibration environments-an update. Clin. Biomech., 11: 61-73. DOI: 10.1016/02680033(95)00039-9 